\title{
Distributional Effects of Public Education in an Economy with Public Pensions*
}

\author{
By Gerhard Glomm and Michael Kaganovich ${ }^{1 \#}$ \\ Indiana University, U.S.A.
}

\begin{abstract}
We study how the allocation of government expenditures between two major outlays--education and pay-as-you-go social security--affects human capital distribution in an economy with heterogeneous agents. We consider an overlapping generations economy where the government maintains both programs, and allocates tax revenues to finance them. In our model, human capital is one of the factors of production. It is itself produced as a combined result of public inputs and private inputs. Parents' decisions to invest time and material resources in education of their children are motivated by altruism, heterogeneous in its strength across the population, which leads to heterogeneity of incomes. We investigate the effect of an increase in public funding for education on the human capital distribution. We show that in this framework, contrary to some earlier results, increased spending on public education may lead to higher inequality. Our results depend crucially on the interaction of education funding with the social security budget and on the elasticity of substitution in the learning technology.

JEL classification: $\mathrm{H} 50, \mathrm{D} 90, \mathrm{O} 15$
\end{abstract}

Running head: Distribution and Public Education

* Manuscript received April 2000; revised March 2002.

\# E-mail: gglomm@indiana.edu; mkaganov@indiana.edu

${ }^{1}$ We are grateful to Richard Rogerson and two anonymous referees for insightful comments and suggestions, and to Xuejuan Su for research assistance. We also appreciate comments from Edi Karni, Larry Kotlikoff, Luisa Lambertini, Jonathan Parker, Pierre Pestieau, Peter Rangazas, Antonio Rangel, seminar participants at Ben Gurion University, FRB of Minneapolis, Indiana University, IUPUI, and Stanford Institute for Theoretical Economics, and conference participants at the 1999 Summer Meetings of the Econometric Society, 1999 SED Meetings, 1999

Conference on Intergenerational Transfers, Taxes and the Distribution of Wealth at Uppsala, and 2002 Midwest Macroeconomics Conference. Responsibility for any remaining errors is ours. 


\section{Introduction}

In practically all countries governments directly provide education to school age children. Also, in many countries, especially the relatively rich ones, governments transfer resources from the young to the old in the form of social security systems. Both government programs have a redistributive component. Horace Mann, the "father of public education" in the United States argued in the middle of the nineteenth century that public education is "beyond all other devices of human origin, the great equalizer of the condition of men...” (p.87, Cremin (1957)). More recently, the United States Supreme Court in Brown v Board of Education, declared that education "must be made available to all on equal terms." At the inception of the social security program in the United States in the 1930s, its redistributional aspects were common political arguments in its favor (see Miron and Weil, 1997).

There are large bodies of literature studying both programs in isolation. Benabou (1996), Boldrin (1993), Fernandez and Rogerson (1996), Eckstein and Zilcha (1994), Glomm and Ravikumar (1992), Hanushek et al. (2001) and many others study public education. The literature on social security includes Feldstein (1974, 1982), Hubbard and Judd (1987), Karni and Zilcha (1989), and Laitner (1988, 2001). In each of these papers, one specific government program is evaluated in isolation from any other government program. Rios-Rull (1996) questions the usefulness of such one-dimensional models.

In this paper we study how effective uniform and universal public expenditures on education are at redistribution, when the government also runs a pay-as-you-go social security system. Our paper adds to a small literature that analyzes both public programs jointly. Boldrin and Alonso (2000) study how public funds are allocated to education or social security in game played between generations. They derive efficiency conditions and find that these efficiency 
conditions and data from Spain fit well. Kaganovich and Zilcha (1999) examine the growth effect of shifting public funds from social security to education. They find conditions under which such a shift actually lowers growth. Soares (2001) analyzes how decentralization of the education system influences growth in a model in which the government also runs a social security system. Some authors have also analyzed interactions between publicly funded social security system and privately funded education. Zhang and Zhang (1998) find that a PAYG social security program can actually speed up economic growth when there are interaction effects with fertility and investment in human capital. Pecchenino and Utendorf (1999) consider a similar setting but assume exogenous fertility; under some conditions they obtain a result opposite to that of Zhang and Zhang (1998): on the margin, social security crowds out education and lowers growth.

We concentrate on dynamic distributional effects of raising funding levels for public education, in the presence of PAYG social security system. We pursue the standard comparative dynamics framework for such an analysis, where distributions in a dynamic competitive equilibrium resulting from a policy shock are compared at each point in time to distributions along the economy's original trajectory. ${ }^{2}$ A similar policy experiment is addressed by Biggs and Dutta (1999), who use a model of public and private schooling to simulate the effects of changing funding levels for public education on income inequality. They find that decreasing funding for public education can increase inequality in the long run, but their model does not take public funding for social security into consideration. We show that, in fact, taking public pensions into account makes a significant difference for policy effects.

\footnotetext{
${ }^{2}$ Note the distinction from an analysis of evolution of inequality, which would involve
} comparing distributions on the same trajectory but at different points in time. 
In order to study the effects of public expenditures on education and intergenerational transfers on inequality we employ an overlapping generations model, which is described in Section 2. Each individual lives two periods, values consumption in both periods, but only works in the first period of life. Generations are altruistically linked: Individuals derive utility from the human capital of their off-springs. This altruistic motive is heterogeneous across individuals within a generation. We use this modeling assumption as a device to generate a human capital distribution within each generation. Physical capital is financed by private savings of the working adults. Human capital is produced using three inputs: a publicly provided material input, effective parental time, and a privately provided material input. It will turn out that the degree of substitutability between the private inputs and the government input is crucial. We allow for both complementarity and substitutability.

In our model the government collects taxes on labor income at a uniform rate. Tax revenue is used to fund PAYG social security and public education. We study how increases in funding for public education influence inequality in terms of the resulting distribution of human capital. Supposing that the government's policy is to increase the tax rate for public education, we consider the possibility of adverse tax interaction effects on the tax revenue raised for transfers to the old; we then analyze the overall impact of the government policy on inequality.

In Section 3, we consider the benchmark case of our model, where private material inputs in education do not enter the picture. In this case, the public input and effective parental time are two inputs in a Cobb-Douglas human capital production function, hence the two inputs are in a complementary relationship. Our results in this section are: (i) When there are no tax-interaction effects, increasing funding for public education has no effect on inequality; (ii) When raising the 
education tax has any (however small) effect on the social security's share of national income, raising the public education tax will increase inequality.

In Section 4, we solve the model for the general case when private material inputs do play a role in the production of human capital. When there are no tax interaction effects at all, we find that increasing the education tax reduces inequality. In the extreme alternative case, where public expenditures on education and social security are funded from a general pool of nonearmarked tax revenues (tax interaction is extreme), we find that spending more on public education can have a non-monotonic effect on inequality in this model. Our paper shows that the distributional effects of increasing public education funding depend upon individual responses to both government programs and on their budgetary interaction. The extent of these interactions, in fact, varies substantially across countries. Hence our results may offer helpful insights in analyzing the distributional effects as they depend on the institutional characteristics of public programs.

Section 5 concludes and offers an agenda for future research.

\section{The Model}

We study an overlapping generations economy with heterogeneous agents. We assume that each agent belongs to a dynasty indexed by the family name $\omega \in \Omega$, where $\Omega$ spans the entire population in any generation. At each time $t$ each dynasty is represented by one young and one old adult, i.e., each individual lives for two periods, youth and old age, and the population does not change over time. Let $\mu$ be the Lebesgue measure on $\Omega$ with $\mu(\Omega)=1$. Let $h_{t}(\omega)$ be the human capital, as well as the effective labor supply, of young adult $\omega$ of generation $\mathrm{t}$. Then 


$$
\mathrm{H}_{\mathrm{t}}=\int_{\Omega} \mathrm{h}_{\mathrm{t}}(\omega) \mathrm{d} \mu(\omega)
$$

is both aggregate and mean (per capita) human capital of generation $t$.

Preferences of any individual in generation $t$ are given by the utility function

$$
\alpha_{1} \ln \mathrm{c}_{\mathrm{t}, \mathrm{t}}+\alpha_{2} \ln \mathrm{c}_{\mathrm{t}, \mathrm{t}+1}+\alpha_{3} \ln \mathrm{h}_{\mathrm{t}+1}
$$

where $c_{t, t}$ and $c_{t, t+1}$ are his consumption when young and when old, respectively, and $h_{t+1}$ is the human capital of his offspring. The coefficients $\alpha_{i}>0$ for $i=1,2$ are identical for all agents while $\alpha_{3}>0$, expressing the degree of agent's altruistic concern about the human capital of his offspring, is allowed to vary across agents in all generations. Specifically, for an individual $\omega$ in generation $\mathrm{t}$, let $\alpha_{3}(\omega, \mathrm{t})$ be a realization of a random variable drawn from a distribution given by the probability measure $\mathrm{P}($.$) , which is identical for all individuals, independent of their human$ capital, and does not change over time. It is assumed that there are numbers $\mathrm{c}_{1}>0, \mathrm{c}_{2}<\infty$ such that $c_{1} \leq \alpha_{3}(\omega, t) \leq c_{2}$ for all $\omega, t$. Each young individual learns his realization $\alpha_{3}(\omega, t)$ prior to making his resource allocation decision. The arguments in $\alpha_{3}(\omega, t)$ will be sometimes omitted for brevity.

The heterogeneity of preferences obviously leads to heterogeneity in individual decisions, outcomes, and endowments in each generation, hence all the respective variables in the model are functions of $\omega$, although this argument will sometimes be omitted for brevity. A young agent in generation t of the family $\omega$ is endowed with human capital (effective labor capacity) $h_{t}(\omega)$ and a unit of time which he splits between child rearing and work. We denote by $n_{t}(\omega)$ the fraction of time he devotes to child rearing, hence his labor income is given by $\mathrm{w}_{\mathrm{t}} \mathrm{h}_{\mathrm{t}}(\omega)\left(1-\mathrm{n}_{\mathrm{t}}(\omega)\right)$, where $\mathrm{w}_{\mathrm{t}}$ is the wage rate at time $\mathrm{t}$ per unit of the effective labor. This income is allocated to the agent's current consumption $c_{t, t}(\omega)$, his private investment $e_{t}(\omega)$ in education of the 
offspring, as well as savings $\mathrm{s}_{\mathrm{t}}(\omega)$ required to finance his own old-age consumption $\mathrm{c}_{\mathrm{t}, \mathrm{t}+1}(\omega)$. Individuals are also allowed to borrow when young, in which case the variable $\mathrm{s}_{\mathrm{t}}(\omega)$ has a negative value. We assume that individuals use up savings or repay any loans when old, and that the lending and borrowing interest rates are the same; the interest rate applied at time $\mathrm{t}$ will be denoted by $\mathrm{r}_{\mathrm{t}}$.

We assume that the economy's aggregate production function is

$$
\mathrm{Y}_{\mathrm{t}}=\mathrm{AK}_{\mathrm{t}}^{\delta} \widetilde{\mathrm{H}}_{\mathrm{t}}^{1-\delta}
$$

where $Y_{t}$ is total output, $K_{t}$ is the aggregate stock of physical capital, $\widetilde{\mathrm{H}}_{\mathrm{t}}=\int_{\Omega} \mathrm{h}_{\mathrm{t}}(\omega)\left(1-\mathrm{n}_{\mathrm{t}}(\omega)\right) \mathrm{d} \mu(\omega)$ is the aggregate input of effective labor in period $\mathrm{t}$, and parameters satisfy $\mathrm{A}>0,0<\delta<1$. Physical capital $\mathrm{K}_{\mathrm{t}}$ is financed by the savings of the previous generation, $\mathrm{s}_{\mathrm{t}-1}(\omega)$.

Human capital $h_{t+1}(\omega)$ of a young individual in generation $t+1$ is produced using parental time $n_{t}(\omega)$, material private inputs $e_{t}(\omega)$, as well as public expenditures on education, which are uniform and universal in our model: all children of generation $t$ receive public input at the same level $\mathrm{X}_{\mathrm{t}}$, free of charge. The human capital production function is assumed to have the form:

$$
h_{t+1}(\omega)=B\left(h_{t} n_{t}\right)^{\sigma}\left(X_{t}+b e_{t}\right)^{\eta}
$$

where $\mathrm{B}>0, \mathrm{~b} \geq 0,0<\sigma<1,0<0<1$, and $\sigma+0 \leq 1$. If $\mathrm{b}=0$ this is similar to the learning technology in Lucas (1988) and identical to the learning technology in Benabou (1996), Boldrin (1993), Glomm and Ravikumar (1992), Loury (1981) and Zhang (1996). In this specification, effective parental time exhibits complementarity to the publicly provided input $\mathrm{X}_{\mathrm{t}}$. This formulation of the learning technology is consistent with findings by Tsiddon and Rubinstein (1999) that parents' education can explain wage growth of their children. The 
assumption of a complementary relationship between private and public inputs in education is also supported by the evidence presented in LeGrand (1982). LeGrand argues that "there are income related inequalities in the use of the services that affect outcomes", even if there is uniform and universal provision of these public services. When $b>0$, the education technology involves a private input $e_{t}$ which is a perfect substitute for the publicly provided input. The motivation for allowing for this possibility of substitution is given by recent research by Houtenville and Conway (2001), which suggests that parental contribution to children's education is reduced as public school quality rises. A similar technology specification with perfect substitutability of public and private inputs in education was considered by Soares (2001). Note that with $\mathrm{F}+0 \leq 1$, i.e., constant or decreasing returns in the education sector, we allow for both the long run sustainable growth as well as convergence to a steady state. Our results on comparative dynamics of inequality obtained here apply to both cases.

As stated earlier, the government runs two public programs, each financed by taxes on labor income of working adults. For simplicity, we assume that the tax to finance public education is collected at constant and uniform rate J. Similarly, the pay-as-you-go social security system is funded by a payroll tax with constant and uniform rate 2 . Obviously, J $+2<1$ should be assumed. Recall that aggregate wage income in period $t$ is given by $w_{t} \widetilde{H}_{t}$. Therefore, according to these specifications and assuming that the government budget is balanced in each period, we obtain the aggregate levels of current transfers to education and retirees, respectively:

$$
\begin{aligned}
& X_{t}=\tau w_{t} \widetilde{H}_{t} \\
& T_{t}=\theta w_{t} \widetilde{H}_{t}
\end{aligned}
$$


Our framework allows for a possibility of budgetary competition between the programs. Namely, in our main comparative dynamics exercise involving a marginal increase of the education tax rate J, we will consider different possible (non-positive) values of the derivative $\frac{\partial \theta}{\partial \tau}$. One extreme possibility is $\frac{\partial \theta}{\partial \tau}=0$, i.e., two public programs are run independently: an education tax rate hike has no direct effect on the fraction of national income devoted to social security (thus an increase of the education tax rate $J$ translates directly into the same increase of the aggregate rate $J+2)$. We can think of this as an economy in which there are two separate pools of public funds. This corresponds to an idealized institutional arrangement in the U.S., where public education is for the most part funded by state and local governments and where social security is funded by the federal government.

The other extreme, $\frac{\partial \theta}{\partial \tau}=-1$, means that two programs come out of the same pool of revenue, while the aggregate rate of taxation $J+2$ stays constant. This might be a good description of financing regimes in countries with centralized governments, like France, where it is difficult to raise taxes so that additional expenditures on education must come at the expense of the social security budget.

The real picture in most economies belongs between those extremes $-1<\frac{\partial \theta}{\partial \tau}<0$. Even in the US, where education funding draws from a mix of tax bases mostly at the state and local levels, it includes a considerable and growing federal component. Given that substantial portions of Social Security and Medicare funds in the US are also allocated from the general federal budget, these programs are in competition with public education funding in the budgetary process 
but also through the political process, which imposes limits on growth of the aggregate tax burden. Moreover, state and local taxes may be deductible from federal taxes and hence diminish overall federal tax revenues which may negatively affect transfers to the old from the general budget.

Our specification treats both redistributive programs symmetrically. In both the case of public education and the case of social security, the tool for redistribution acts like a linear tax: Tax collection is a linear function of individual income and the governmental expenditure is distributed to households in equal amounts.

According to the model's description, an individual in generation $t$ of the family $\omega$ solves the problem

$$
\begin{array}{ll}
\max & \alpha_{1} \ell n c_{t, t}+\alpha_{2} \ell n c_{t, t+1}+\alpha_{3}(\omega, t) \ell n h_{t+1} \\
\left\{e_{t}, s_{t}\right\} & \\
\text { s.t. } \quad c_{t, t}+e_{t}+s_{t}=(1-\tau-\theta) w_{t} h_{t}\left(1-n_{t}\right) \\
c_{t, t+1}=\left(1+r_{t+1}\right) s_{t}+T_{t+1} \\
h_{t+1}=B\left(h_{t} n_{t}\right)^{\sigma}\left(X_{t}+b e_{t}\right)^{\eta} \\
e_{t} \geq 0, c_{t, t} \geq 0, c_{t, t+1} \geq 0
\end{array}
$$

taking the values of $\mathrm{w}_{\mathrm{t}}, \mathrm{r}_{\mathrm{t}+1}, \tau, \mathrm{T}_{\mathrm{t}+1}, \mathrm{X}_{\mathrm{t}}$ as given.

Note that specification of social security transfers $T_{t+1}$ in (2.3) and (2.4) corresponds to a "pay-as-you-go" system.

Based on the above description we can now define a competitive equilibrium in this overlapping generations economy. 
Definition 2.1: A competitive equilibrium is a collection of sequences of distributions of individual household decisions $\left\{c_{t, t}, c_{t, t+1}, s_{t}, e_{t}, n_{t}, h_{t+1}\right\}_{t=0}^{\infty}$, sequences of aggregate stocks of physical and human capital $\left\{K_{t}, H_{t}\right\}_{t=0}^{\infty}$, sequences of factor prices $\left\{w_{t}, 1+r_{t+1}\right\}_{t=0}^{\infty}$, and

sequences of government expenditures $\left\{T_{t+1}, X_{t}\right\}_{t=0}^{\infty}$ such that:

(i) For each $\omega \in \Omega$ and $t=0,1, \ldots$, the collection $c_{t, t}(\omega), c_{t, t+1}(\omega), s_{t}(\omega), e_{t}(\omega), n_{t}(\omega), h_{t+1}(\omega)$ solves the individual household's maximization problem (2.3);

(ii) Capital markets clear, so the aggregate capital stocks are given by

$$
\begin{aligned}
& K_{t+1}=\int_{\Omega} s_{t}(\omega) d \mu(\omega) \\
& H_{t}=\int_{\Omega} h_{t}(\omega) d \mu(\omega) ;
\end{aligned}
$$

(iii) Factor prices are determined by

$$
\begin{aligned}
& 1+r_{t+1}=\delta Y_{t+1} / K_{t+1}=\delta A K_{t+1}^{\delta-1} \widetilde{H}_{t+1}^{\delta-1} \\
& w_{t}=(1-\delta) Y_{t} / K_{t}=(1-\delta) A K_{t}^{\delta} \widetilde{H}_{t}^{-\delta}
\end{aligned}
$$

(iv) Government expenditures on social security and education are given, respectively, by

$$
\begin{aligned}
& T_{t+1}=\tau(1-\delta) Y_{t+1} \\
& X_{t}=\theta(1-\delta) Y_{t} .
\end{aligned}
$$

\section{The benchmark case: no private material inputs in education}

In this section we assume that $b=0$. In other words, we assume that effective time of a parent is the only private input into production of child's human capital. This is the framework analyzed by Benabou (1996), Boldrin (1993) and Glomm and Ravikumar (1992), and it is similar to the 
learning technology in Loury (1981). Our treatment of parental effective labor in the learning technology corresponds to the one introduced by Lucas (1988).

This section examines how increasing public finds for education influences inequality when the public and private inputs in the learning technology exhibit complementarity. In the benchmark case considered here the private input is represented by effective time. Our results obtained here, however, would remain valid if the private inputs were represented by privately purchased goods such as computers, books, museum tours, etc., as long as a complementary relationship between private and public inputs prevails. Indeed, the complementary relationship between the public and the private input in the learning technology (i.e., the assumption made in much of the existing literature cited above) is essential for the results of this section. For details of the workings of the model when the private complementary input consists of material resources see Glomm and Kaganovich (2001).

When $\mathrm{b}=0$, private households in period $t$ solve the problem

$$
\begin{aligned}
& \max \alpha_{1} \ln \left[(1-\tau-\theta) w_{t} h_{t}\left(1-n_{t}\right)-s_{t}\right]+\alpha_{2} \ln \left[\left(1+r_{t+1}\right) s_{t}+T_{t+1}\right]+\alpha_{3} \sigma \ln n_{t} . \\
& \left\{s_{t}, n_{t}\right\}
\end{aligned}
$$

The first-order conditions for an interior solution are

$$
\begin{aligned}
\frac{\alpha_{2}(1-\tau-\theta) w_{t} h_{t}}{(1-\tau-\theta) w_{t} h_{t}\left(1-n_{t}\right)-s_{t}} & =\frac{\alpha_{3} \sigma}{n_{t}} \\
\frac{\alpha_{1}}{(1-\tau-\theta) w_{t} h_{t}\left(1-n_{t}\right)-s_{t}} & =\frac{\alpha_{2}\left(1+r_{t+1}\right)}{\left(1-r_{t+1}\right) s_{t}+T_{t+1}} .
\end{aligned}
$$

We do not assume any credit constraints, so $s_{t}$ is allowed to be negative. Equations (3.1) and (3.2) allow us to write the decision rules for individuals as 


$$
s_{t}=\frac{\alpha_{2}}{\alpha_{1}+\alpha_{2}+\alpha_{3} \sigma}(1-\tau-\theta) w_{t} h_{t}-\left(1-\frac{\alpha_{2}}{\alpha_{1}+\alpha_{2}+\alpha_{3} \sigma}\right) \frac{T_{t+1}}{1+r_{t+1}}
$$

and

$$
n_{t} h_{t}=\frac{\alpha_{3} \sigma}{\alpha_{1}+\alpha_{2}+\alpha_{3} \sigma}\left[h_{t}+\frac{T_{t+1}}{(1-\tau-\theta) w_{t}\left(1+r_{t+1}\right)}\right]
$$

Recall that

$$
T_{t+1}=\theta(1-\delta) Y_{t+1}, \quad 1+r_{t+1}=\delta Y_{t+1} / K_{t+1}
$$

while $K_{t+1}=\int_{\Omega} s_{t}(\omega) d \mu(\omega)$. We can thus write

$$
\frac{T_{t+1}}{1+r_{t+1}}=\theta(1-\delta) \delta^{-1} K_{t+1}=\theta(1-\delta) \delta^{-1} \int_{\Omega} s_{t}(\omega) d \mu(\omega)
$$

Substitution of (3.5) into (3.3) and integration yields, using independence of $\alpha_{3}$ and $h_{t}$,

$$
K_{t+1}=\frac{\delta \alpha_{2} C(1-\tau-\theta)}{\delta+\left(1-\alpha_{2} C\right) \theta(1-\delta)} w_{t} H_{t},
$$

where $C=\int \frac{d P}{\alpha_{1}+\alpha_{2}+\alpha_{3}(w) \sigma}$. Now, if we substitute (3.6) into (3.5), we obtain

$$
\frac{T_{t+1}}{1+r_{t+1}}=\frac{\theta(1-\delta) \alpha_{2} C(1-\tau-\theta)}{\delta+\left(1-\alpha_{2} C\right) \theta(1-\delta)} w_{t} H_{t}
$$

so that equation (3.4) can be written as

$$
\mathrm{n}_{\mathrm{t}} \mathrm{h}_{\mathrm{t}}=\frac{\alpha_{3} \sigma}{\alpha_{1}+\alpha_{2}+\alpha_{3} \sigma}\left[\mathrm{h}_{\mathrm{t}}+a(\tau, \theta) \mathrm{H}_{\mathrm{t}}\right]
$$

where $a(\tau, \theta)=\theta(1-\delta) \alpha_{2} C\left[\delta+\left(1-\alpha_{2} C\right) \theta(1-\delta)\right]^{-1}$.

According to the definition of learning technology in (2.2) and due to (3.8), we obtain the law of motion for the distribution of human capital in the economy, for the case $b=0$ : 


$$
\mathrm{h}_{\mathrm{t}+1}=\mathrm{B}\left(\frac{\alpha_{3} \sigma}{\alpha_{1}+\alpha_{2}+\alpha_{3} \sigma}\right)^{\sigma} \mathrm{X}_{\mathrm{t}}^{\eta} \mathrm{H}_{\mathrm{t}}^{\sigma}\left[\frac{\mathrm{h}_{\mathrm{t}}(\tau, \theta)}{\mathrm{H}_{\mathrm{t}}}+\mathrm{a}(\tau, \theta)\right]^{\sigma}
$$

We will now study the effect of an increase in the education tax rate $J$ on the distribution of human capital. The standard tool for the comparisons of distributions is given by the Lorenz curves, introduced in Definition 3.1 below. They provide a straightforward partial ordering of distributions (see Atkinson (1970) and Rothschild and Stiglitz (1973)) as stated hereby in Definition 3.2.

Consider the distribution of human capital $\mathrm{h}_{\mathrm{t}+1}(\omega)$ at time $\mathrm{t}+1$ across the population, i.e., over $\omega \in \Omega$. For any number $\xi \in[0,1]$, let $h_{\xi}$ stand for the $100 \xi$-th percentile of the distribution of $\mathrm{h}_{\mathrm{t}+1}(\omega)$, i.e., $\mu\left(\left\{\omega \in \Omega \mid \mathrm{h}_{\mathrm{t}+1}(\omega) \leq \mathrm{h}_{\xi}\right\}\right)=\xi$. Consider also the set $\mathrm{U}_{\xi}=\left\{\omega \in \Omega \mid \mathrm{h}_{\mathrm{t}+1}(\omega) \leq\right.$ $\mathrm{h}_{\xi \xi}$-- the support of the $100 \xi$-th percentile.

Definition 3.1: For a given distribution $\mathrm{h}_{\mathrm{t}+1}$, consider the value

$$
\rho\left(\xi, h_{t+1}\right)=\frac{\int_{U_{\xi}} h_{t+1}(\omega) d \mu(\omega)}{\int_{\Omega} h_{t+1}(\omega) d \mu(\omega)},
$$

which represents the share of total human capital obtained by the least educated $100 \xi \%$ of the population. The function $\rho\left(\xi, \mathrm{h}_{\mathrm{t}+1}\right)$ of $\xi \in[0,1]$ defines the Lorenz curve associated with the distribution $\mathrm{h}_{\mathrm{t}+1}$.

Note that according to the above definition we can rewrite (3.10) as

$$
\rho\left(\xi, I_{t+1}\right)=\frac{E\left(h_{t+1}(\omega) \mid U_{\xi}\right) \times \xi}{E\left(h_{t+1}(\omega)\right)},
$$


where $E\left(h_{t+1}(\omega)\right)=\int_{\Omega} h_{t+1}(\omega) d \mu(\omega)$ and the support set $\mathrm{U}_{\xi}$ is as in definition 3.1, so $:\left(\mathrm{U}_{\xi}\right)=>$ and $E\left(h_{t+1} \mid U_{\xi}\right)=\xi^{-1} \int_{U_{\xi}} h_{t+1}(\omega) d \mu(\omega)$. Recall also that $\mathrm{E}\left(\mathrm{h}_{\mathrm{t}+1}(\omega)\right)=\mathrm{H}_{\mathrm{t}+1}$ under our normalization convention.

Definition 3.2: Distribution $h$ is said to be more equal than a distribution $\widetilde{h}$, if the Lorenz curve associated with distribution $h$ is located above that associated with $\widetilde{h}$, i.e.,

$$
\rho(\xi, \mathrm{h})>\rho(\xi, \tilde{h}) \quad \text { for all } \xi \in[0,1]
$$

In other words, given any $\xi \in[0,1]$, the share of total human capital obtained by the least educated $100 \xi \%$ of the population under the distribution $\mathrm{h}$ is higher than such share under the distribution $\widetilde{\mathrm{h}}$. We will denote the relationship of distributions satisfying condition (3.12) as $\mathrm{h}>_{\mathrm{L}} \tilde{\mathrm{h}}$.

We will use the following basic properties of the Lorenz curves in our comparative dynamics analysis. Their proofs are straightforward.

Lemma 3.1. Let $X$ be a random variable and $P, Q$ constants such that $P>Q$. Then $X+P>_{L}$ $\mathrm{X}+\mathrm{Q}$.

Lemma 3.2. Let $X$ and $Y$ be random variables such that $X>_{L} Y$ and let $0<F<1$. Then $X^{F}>_{L}$ $\mathrm{Y}^{\mathrm{F}}$.

Lemma 3.3. Let $X$ and $Y$ be random variables such that $X>_{L} Y$ and let $Z$ be a positive random variable which has compact support and is independent of variables $\mathrm{X}$ and $\mathrm{Y}$. Then $\mathrm{XZ}>_{\mathrm{L}} \mathrm{YZ}$. 
According to equality (3.9), for any $t=0,1, \ldots$, the distribution of human capital $h_{t+1}(\omega)$ at time $t+1$ is based on the distribution of human capital at time $t$ and the realizations of parameters $\alpha_{3}(\omega)$ at time $t$ which are distributed independently of $h_{t}(\omega)$. We will now consider a policy experiment: we let the tax rate $\mathrm{J}$ increase at a time $\mathrm{t}=0$ and examine the effect of this on the Lorenz curves $\rho\left(\xi, h_{t}\right)$ of human capital distributions in the economy in subsequent time periods along the competitive equilibrium path.

Observe that the factor $\mathrm{BX}_{\mathrm{t}}^{\eta} \mathrm{H}_{\mathrm{t}}^{\sigma}$ in (3.9) is the same for all agents of generation $t$, while $\left(\frac{\alpha_{3} \sigma}{\alpha_{1}+\alpha_{2}+\alpha_{3} \sigma}\right)^{\sigma}$ is distributed independently of $h_{t}(\omega)$. Therefore, according to Lemmas 3.3 and 3.2, Lorenz ranking of the distributions of $h_{t+1}$ is determined by Lorenz ranking of the distributions of $\frac{\mathrm{h}_{\mathrm{t}}(\tau, \theta)}{\mathrm{H}_{\mathrm{t}}}+a(\tau, \theta)$. Now, according to Lemma 3.1, it is evident that the direction in which a change in public policy parameter at time $\mathrm{t}$ will affect the Lorenz ranking of the distributions of $h_{t+1}$ depends on the sign of the derivative of $a(\tau, \theta)$ with respect to the parameter. This argument leads to the following results characterizing distributional effects along the competitive equilibrium path. See Appendix 1 for the detailed proofs.

Recall that in our model $\tau$ is the tax rate used to fund public education, and $\theta$ is the tax rate used to fund social security payments. We first suppose that both tax rates are completely independent of each other, that is $\frac{\partial \theta}{\partial \tau}=0$. This might be the case when the two programs are funded by different levels of government and there are no tax interaction effects. We then have Proposition 3.1: Let $\frac{\partial \theta}{\partial \tau}=0$; then 
(i) Raising the public education tax $\tau$ at time $\mathrm{t}=0$ leaves inequality of human capital, as measured by the Lorenz curve rankings, unaffected in all subsequent periods $t=1,2, \ldots$.

(ii) Raising the social security tax at $\mathrm{t}=0$ will reduce the inequality of human capital, as measured by the Lorenz curve rankings, in all subsequent periods $\mathrm{t}=1,2, \ldots$.

Next we consider possible interaction effects between the two taxes. One extreme case is when there is a common budget constraint for the two government programs and any increase in funding for one of them must come dollar for dollar at the expense of the other. In this case $\frac{\partial \theta}{\partial \tau}=-1$, which is the extreme alternative of the assumption $\frac{\partial \theta}{\partial \tau}=0$

In the US, most public education expenditures are incurred at the local or state level. Since local taxes are deductible from federal taxation and a significant part of the transfers to the old are financed out of general (federal) revenue, one might expect that $-1<\frac{\partial \theta}{\partial \tau}<0$.

Proposition 3.2: Let $-1 \leq \frac{\partial \theta}{\partial \tau}<0$; then

(i) if $2>0$, i.e., there is a social security program, then an increase in the education tax $\tau$ at time $\mathrm{t}=0$ will increase inequality of the distribution of human capital, as measured by the Lorenz curve rankings, in all subsequent periods $\mathrm{t}=1,2, \ldots$

(ii) if $2=0$, i.e., there is no social security program, then an increase in the education tax $\tau$ at time $\mathrm{t}=0$ will leave inequality of the distribution of human capital, as measured by the Lorenz curve rankings, unaffected in all subsequent periods $t=1,2, \ldots$ 
Notice that the presence of social security is crucial for the results in this section. It is evident from equation (3.4) that, when social security transfers are zero, parental time allocated to a child's schooling is a constant number. In such a case, changing funding for public education does not change inequality according to the Lorenz criterion at all, since changing public education funding only brings about proportional changes in human capital stocks and does not alter individual responses.

On the other hand, when the government runs a social security program, private individuals take the size of these transfers into consideration when making their decisions. Changing public funding for education has distributional effects, not only because of taxinteraction effects, but also because of individual responses to changes in policy, in terms of their time allocations by individuals to children's education, given that these responses depend upon parental stock of human capital. The effect of changing public funding of education on inequality takes place in our model only as a result of changing parental effective time $n_{t} h_{t}$ invested in children'education. Notice in equation (3.4) that optimal parental effective time allocated to schooling a child depends linearly on parents' human capital while public policy affects only the intercept term. Whether this intercept term rises or falls, after all the general equilibrium effects are worked out, determines the distributional effects of changing public funding for education. Increasing funding for education lowers after-tax income, which in turn lowers savings and future physical capital. This decreases income available for social security transfers and raises the interest rate. When there are no tax interaction effects at all, i.e. when $\frac{\partial \theta}{\partial \tau}=0$, these effects exactly cancel out and inequality is unaffected. 
When there are any tax interaction effects, increasing public education funding lowers the equal transfer individuals receive through social security. This absolute decrease has a bigger impact at the bottom of the distribution. Thus, an increase in public education funding increases inequality. This result challenges a belief that increasing public education funding has an equalizing effect (see for example Horace Mann (1848) (as quoted by Cremin (1957)), Coons, Clune and Sugarman (1970) and Thurow (1972)). Few of these claims rest on fully specified general equilibrium models. Others, like Eckstein and Zilcha (1994), who derive this conclusion in OLG models, ignore the possible impact of increased public education expenditure on other publicly funded programs that compete for the same tax revenues and the resulting negative effect on individual incentives to provide private inputs in education. Our result in Proposition 3.2 states the opposite: increased funding for public education generates higher inequality. The apparent contradiction is explained by the interaction between two public programs in our model. Here, higher spending on public education means a relative reduction in funding social security, which distorts the agents' incentives to invest private resources in the education of their children.

\section{Substitution between public and private inputs in the learning technology}

In this section we will analyze the model in case $b>0$. This allows us to study how changing the substitution elasticity between public and private inputs influences our results of the previous

section. We will focus here on the two extreme alternative cases: when $\frac{\partial \theta}{\partial \tau}=0$ (no tax

interaction effects between two programs) or $\frac{\partial \theta}{\partial \tau}=-1$ (extreme tax interaction, such that the

total tax rate remains constant).

A household in generation $t$ solves the following problem 
$\max \quad \alpha_{1} \ln \left[(1-\tau) \mathrm{w}_{\mathrm{t}} \mathrm{h}_{\mathrm{t}}\left(1-\mathrm{n}_{\mathrm{t}}\right)-\mathrm{s}_{\mathrm{t}}-\mathrm{e}_{\mathrm{t}}\right]+\alpha_{2} \ln \left[\left(1+\mathrm{r}_{\mathrm{t}+1}\right) \mathrm{s}_{\mathrm{t}}+\mathrm{T}_{\mathrm{t}+1}\right]+\alpha_{3} \sigma \ln \mathrm{n}_{\mathrm{t}}+\alpha_{3} \eta \ln \left(\mathrm{X}_{\mathrm{t}}+\mathrm{be}_{\mathrm{t}}\right)$ $\left\{s_{t}, e_{t}, n_{t}\right\}$

Notice that this maximization problem has a potentially binding non-negativity constraint on $e_{t}$.

We will limit consideration to the case of interior solution, and will later explore conditions which guarantee this. The first order conditions in case of an interior solution are

$$
\begin{gathered}
\frac{\alpha_{1}(1-\tau) w_{t} h_{t}}{(1-\tau-\theta) w_{t} h_{t}\left(1-n_{t}\right)-s_{t}-e_{t}}=\frac{\alpha_{3} \sigma}{n_{t}} \\
\frac{\alpha_{1}}{(1-\tau-\theta) w_{t} h_{t}\left(1-n_{t}\right)-s_{t}-e_{t}}=\frac{\alpha_{2}\left(1+r_{t+1}\right)}{\left(1+r_{t+1}\right) s_{t}+T_{t+1}} \\
\frac{\alpha_{1}}{(1-\tau-\theta) \mathrm{w}_{\mathrm{t}} \mathrm{h}_{\mathrm{t}}\left(1-\mathrm{n}_{\mathrm{t}}\right)-\mathrm{s}_{\mathrm{t}}-\mathrm{e}_{\mathrm{t}}}=\frac{\alpha_{3} \eta \mathrm{b}}{\mathrm{X}_{\mathrm{t}}+\mathrm{be}} .
\end{gathered}
$$

Solving these equations yields

$$
\begin{aligned}
& s_{t}=\alpha_{2} d(1-\tau-\theta) w_{t} h_{t}+\alpha_{2} d \frac{X_{t}}{b}-\left(1-\alpha_{2} d\right) \frac{T_{t+1}}{1+r_{t+1}} \\
& e_{t}=\alpha_{3} \eta d(1-\tau-\theta) w_{t} h_{t}-\left[1-\alpha_{3} \eta d\right] \frac{X_{t}}{b}+\alpha_{3} \eta d \frac{T_{t+1}}{1+r_{t+1}} \\
& w_{t} h_{t} n_{t}=\alpha_{3}(1-\eta) d w_{t} h_{t}+\frac{\alpha_{3}(1-\eta) d}{b(1-\tau-\theta)} X_{t}+\frac{\alpha_{3}(1-\eta) d}{(1-\tau-\theta)} \frac{T_{t+1}}{1+r_{t+1}}
\end{aligned}
$$

where $d=d(\omega)=\left[\alpha_{1}+\alpha_{2}+\alpha_{3}(\omega)\right]^{-1}$.

It is now clear from equation (4.2) why the non-negativity constraint on private expenditure on education $e_{t}$ might become binding. Since $e_{t}$ and public expenditures on education $X_{t}$ are perfect substitutes, private expenditure falls as public education expenditure rises. However $e_{t}$ responds positively to old-age support. According to (4.2), the non-negativity 
constraint on $e_{t}$ may become binding if public expenditure on education becomes large relative to social security payments.

Recall the expressions given in (2.3) and (3.5) for the volume of public investment in education and the present value of future transfer to the old, respectively:

$$
\begin{aligned}
& \mathrm{X}_{\mathrm{t}}=\tau \mathrm{w}_{\mathrm{t}} \widetilde{\mathrm{H}}_{\mathrm{t}} \\
& \frac{\mathrm{T}_{\mathrm{t}+1}}{1+\mathrm{r}_{\mathrm{t}+1}}=\theta(1-\delta) \delta^{-1} \mathrm{~K}_{\mathrm{t}+1}
\end{aligned}
$$

Integrating equation (4.1) and using independence of the distributions of $\alpha_{3}$ and $h_{t}$ we therefore obtain

$$
\mathrm{K}_{\mathrm{t}+1}=\left[1+\left(1-\alpha_{2} \mathrm{D}\right) \theta \frac{1-\delta}{\delta}\right]^{-1} \alpha_{2} \mathrm{D}\left[(1-\tau-\theta) \mathrm{w}_{\mathrm{t}} \mathrm{H}_{\mathrm{t}}+\frac{1}{\mathrm{~b}} \mathrm{X}_{\mathrm{t}}\right]
$$

where $D=\int \frac{1}{\alpha_{1}+\alpha_{2}+\alpha_{3}(\omega)} d P$.

Substituting this back in (4.5), we obtain

$$
\frac{T_{t+1}}{1+r_{t+1}}=\frac{\theta(1-\delta) \alpha_{2} D}{\delta+\left(1-\alpha_{2} D\right) \theta(1-\delta)}\left[(1-\tau-\theta) w_{t} H_{t}+\frac{X_{t}}{b}\right]
$$

Combined with (4.2), this helps establish restrictions on parameters of the model that guarantee interior solutions for all agents in terms of their private education expenditure $e_{t}$. Indeed, these relationships show that this will be the case if 2 is sufficiently large relative to J, the parameters $0, \mathrm{~b}$, and " 2 are sufficiently large, while " 3 is never too small. We will impose these restrictions throughout this section, including the numerical results.

Now we integrate (4.3) and apply (4.7) along with the fact $X_{t}=\tau w_{t} \widetilde{H}_{t}$ (as stated in (2.3)). This results in 
$\mathrm{w}_{\mathrm{t}}\left(\mathrm{H}_{\mathrm{t}}-\widetilde{\mathrm{H}}_{\mathrm{t}}\right)=\left[1-\left(\alpha_{1}+\alpha_{2}\right) \mathrm{D}\right] \frac{1-\eta}{1-\tau-\theta}\left[\frac{\delta+\theta(1-\delta)}{\delta+\left(1-\alpha_{2} \mathrm{D}\right) \theta(1-\delta)}\right]\left[(1-\tau-\theta) \mathrm{w}_{\mathrm{t}} \mathrm{H}_{\mathrm{t}}+\frac{1}{\mathrm{~b}} \tau_{\mathrm{w}} \widetilde{\mathrm{H}}_{\mathrm{t}}\right]$

which yields

$$
\widetilde{H}_{t}=A_{1}(\tau, \theta)(1-\tau-\theta) b H_{t}
$$

where

$$
\mathrm{A}_{1}(\tau, \theta)=\frac{\eta[\delta+\theta(1-\delta)]-\theta(1-\delta) \alpha_{2} \mathrm{D}+(1-\eta)[\delta+\theta(1-\delta)]\left(\alpha_{1}+\alpha_{2}\right) \mathrm{D}}{[\delta+\theta(1-\delta)](1-\tau-\theta) \mathrm{b}-\theta(1-\delta) \alpha_{2} \mathrm{D}(1-\tau-\theta) \mathrm{b}+\tau(1-\eta)[\delta+\theta(1-\delta)]\left[1-\left(\alpha_{1}+\alpha_{2}\right) \mathrm{D}\right]}
$$

We will now use this expression to characterize the law of motion of human capital. Combining (4.2) and (4.3) one can obtain

$$
\mathrm{w}_{\mathrm{t}} \mathrm{h}_{\mathrm{t}} \mathrm{n}_{\mathrm{t}}=\frac{(1-\eta)\left(\mathrm{X}_{\mathrm{t}}+\mathrm{be}_{\mathrm{t}}\right)}{(1-\tau-\theta) \mathrm{b \eta}}
$$

Substituting this into the law of motion (2.2) yields

$$
\mathrm{h}_{\mathrm{t}+1}(\omega)=(\mathrm{a} \text { positive coefficient }) \times\left(\mathrm{X}_{\mathrm{t}}+\mathrm{be}_{\mathrm{t}}(\omega)\right)^{\sigma+\eta}
$$

where the coefficient is the same for all agents of generation $t$. Therefore the distribution of $h_{t+1}(\omega)$ has the same Lorenz curves as the distribution of $X_{t}+b_{t}(\omega)$. We will denote such relationship by

$$
\mathrm{h}_{\mathrm{t}+1} \sim\left(\mathrm{X}_{\mathrm{t}}+\mathrm{be}_{\mathrm{t}}\right)^{\sigma+\eta}
$$

Substituting the relationships (4.4) and (4.7) in (4.2) we obtain the expression for private material input in education:

$$
\begin{aligned}
\mathrm{e}_{\mathrm{t}}= & \alpha_{3} \eta \mathrm{d}(1-\tau-\theta) \mathrm{w}_{\mathrm{t}} \mathrm{h}_{\mathrm{t}}+ \\
& +\left\{\frac{\alpha_{3} \eta \mathrm{d}[\delta+\theta(1-\delta)]}{\delta+\left(1-\alpha_{2} \mathrm{D}\right) \theta(1-\delta)}-1\right\} \frac{\tau \mathrm{w}_{\mathrm{t}} \widetilde{\mathrm{H}}_{\mathrm{t}}}{\mathrm{b}}+\frac{\alpha_{3} \eta \mathrm{d}(1-\tau-\theta) \theta(1-\delta) \alpha_{2} \mathrm{D}}{\delta+\left(1-\alpha_{2} \mathrm{D}\right) \theta(1-\delta)} \mathrm{w}_{\mathrm{t}} \mathrm{H}_{\mathrm{t}}
\end{aligned}
$$

where the values $\mathrm{d}$ and $\mathrm{D}$ are as defined in (4.3) and (4.6), respectively. 
Therefore, according to (4.4) and (4.8)

$$
X_{t}+b_{t}=\alpha_{3} \eta d(1-\tau-\theta) w_{t}\left\{h_{t}+A_{2}(\tau, \theta) H_{t}\right\},
$$

where

$$
A_{2}(\tau, \theta)=\frac{\theta(1-\delta) \alpha_{2} D+\tau[\delta+\theta(1-\delta)] A_{1}(\tau, \theta)}{\delta+\left(1-\alpha_{2} D\right) \theta(1-\delta)}
$$

while $A_{1}(\tau, \theta)$ was defined in (4.9).

Since $\alpha_{3} \mathrm{~d}$ is distributed independently of $h_{t}$, while the coefficient $\eta \mathrm{d}(1-\tau-\theta) \mathrm{w}_{\mathrm{t}}$ is the same for all agents, we can conclude, according to (4.10) and due to Lemma 3.3, that

$$
\mathrm{h}_{\mathrm{t}+1}(\omega) \sim\left(\frac{\mathrm{h}_{\mathrm{t}}(\omega)}{\mathrm{H}_{\mathrm{t}}}+\mathrm{A}_{2}(\tau, \theta)\right)^{\sigma+\eta}
$$

Thus, similarly to the results of the previous section, the effect of a change in the education tax rate $J$ on the distribution of human capital is determined by the direction of change of the function $\mathrm{A}_{2}(\tau, \theta)$.

Consider first the case when $\frac{\partial \theta}{\partial \tau}=0$, i.e., when there are no tax interaction effects between public education and social security programs. It is straightforward to show that in this case the derivative $\frac{\partial \mathrm{A}_{2}(\tau, \theta)}{\partial \tau}$ is always positive. This, along with an induction argument used in the proof of Proposition 3.1, establishes the following result:

Proposition 4.1: Let $\frac{\partial \theta}{\partial \tau}=0$; then an increase in the public education tax $\mathrm{J}$ at time $\mathrm{t}=0$ will reduce inequality of human capital, as measured by the Lorenz curve rankings in all the subsequent periods $t=1,2, \ldots$, along the competitive equilibrium path. 
Now let $\frac{\partial \theta}{\partial \tau}<0$, i.e., tax interaction effects are present. In this case signing the derivative $\frac{\partial \mathrm{A}_{2}(\tau, \theta)}{\partial \tau}$ in its relation to the model's parameters is analytically intractable. We therefore use numerical methods to study how $A_{2}(\tau, \theta)$ depends upon the level of public funding for education J. Furthermore, we focus here on the case of extreme tax interaction, $\frac{\partial \theta}{\partial \tau}=-1$. Without carrying out an explicit calibration exercise, we choose reasonable parameters for the numerical solutions. For preference parameters we take $\alpha_{1}=\alpha_{2}=1$. We let $D$ vary between 0.3 and 0.45 so that, on average, the weight $\alpha_{3}$ placed on altruism in preferences is not too large. We choose a standard value for capital's share of income: $\delta=0.3$. The parameter values for the learning technology are perhaps a less settled issue. We let $b$, the parameter measuring the effectiveness of private expenditure on education relative to public such expenditure, vary between 0.5 and 2.0. We are not aware of of reliable estimates of this parameter, so allowing the wide range seems appropriate. For the exponent coefficient for material inputs in education technology 0 we choose values ranging from 0.01 to 0.3 . This range includes, in particular, the estimates obtained by Card and Krueger (1992) for public education. We also assume constant returns in education technology, i.e., $\mathrm{F}+\mathrm{O}=1$, throughout our numerical analysis. For the aggregate tax rate for two public programs $\mathrm{J}+2$ we experimented with values ranging from 0.08 to 0.3 . In all of the numerical analysis we verify that conditions to ensure that the solution for $e_{t}$ is interior for all agents at all times are met.

The numerical solutions reveal the following findings: 
Numerical fact 1. Let $\frac{\partial \theta}{\partial \tau}=-1$. If government size measured by the total tax rate $\mathrm{J}+2$ is large (at least 0.2 ), then an increase in the public education tax rate at $\mathrm{t}=0$ reduces inequality along the competitive equilibrium path.

Note that the above result shows the same effect as established in Proposition 4.1 for the case $\frac{\partial \theta}{\partial \tau}=0$

Numerical fact 2. Let $\frac{\partial \theta}{\partial \tau}=-1$. If the total tax rate $\mathrm{J}+2$ is small, $b$ is large and 0 is relatively small (within the respective ranges specified above), then $A_{2}(\tau, \theta)$ is a decreasing function of public education funding. Hence an increase in the public education tax rate at $\mathrm{t}=0$ will increase inequality along the competitive equilibrium path.

Numerical fact 3. Let $\frac{\partial \theta}{\partial \tau}=-1$. For small values of $\mathrm{J}+2$ and intermediate values of $\mathrm{b}$ (within the respective ranges specified above), the relationship between public education funding and inequality is non-monotonic, exhibiting a U-shaped relationship: when J is relatively small, inequality decreases, along the competitive equilibrium path, if $\mathrm{J}$ is marginally increased at $\mathrm{t}=0$; however, when $\mathrm{J}$ is large, inequality increases if $\mathrm{J}$ is increased at $\mathrm{t}=0$.

See Appendix 2 for representative illustrations of the numerical solutions.

The intuition for the results in this section is as follows. It is clear from the first order conditions that effective learning time $\mathrm{n}_{\mathrm{t}} \mathrm{h}_{\mathrm{t}}$ is linearly related to material inputs in education $X_{t}+b e_{t}$. According to equation (4.10), future human capital is proportional to material inputs $X_{t}+b e_{t}$. Therefore it suffices to explain how changes in public policy influence $X_{t}+b e_{t}$ across 
the human capital distribution. Since $\alpha_{3} \mathrm{~d}$ is distributed independently of $h_{t}$, equation (4.2)

implies

$$
X_{t}+b e_{t} \sim\left[b(1-\tau-\theta) w_{t} h_{t}+X_{t}+b \frac{T_{t+1}}{1+r_{t+1}}\right]
$$

Inspection of equation (4.15) yields the intuition for the results in this section. First assume that there are no tax interaction effects, that is $\frac{\partial \theta}{\partial \tau}=0$. Then, an increase in public education funding $\tau$ increases public material inputs $X_{t}$, as stated in Proposition 4.1. This is true despite a decrease in the tax base $\widetilde{H}_{t}$; the Laffer curve is upward sloping. Notice that, unlike in Section 3, the publicly provided material inputs $X_{t}$ do enter additively. This is precisely because of the perfect substitution property. Thus, an increase in public education funding generates an equal absolute increase in in material inputs in education of each child independent of parental human capital. We call this the "direct education effect", which in this case decreases inequality. But, there is a second effect, which we call the "indirect social security effect." Increasing public funding for education decreases after tax income, which, in turn, decreases accumulation of physical capital and hence the present value of future social security transfers. Increasing public funding for education increases inequality through the social security effect. In our model, when $\frac{\partial \theta}{\partial \tau}=0$, the public education effect dominates the social security effect and raising $\tau$ unambiguously decreases inequality.

When $\frac{\partial \theta}{\partial \tau}<0$, raising public funding for education decreases social security transfers more than when $\frac{\partial \theta}{\partial \tau}=0$. In this case the social security effect can dominate the education effect, 
so that raising public funding for education can increase inequality. Our numerical simulations reveal that the social security effect is likely to dominate the education effect when the productivity of private material inputs relative to public material inputs $b$ is large.

\section{Conclusion}

In this paper we studied how changes in public funding for education influence the distribution of human capital. We used an overlapping generations economy where heterogeneity of human capital levels is driven by differential bequest motives. The punch line of this paper is two-fold: First, the elasticity of substitution between public and private inputs matters for how changing funding for public education affects the distribution of human capital. When public and private inputs are complements, increasing funding for public education increases inequality. This result is reversed when public and some private inputs in education are substitutes. Second, it is crucial for these results that the government fund both public education and a PAYG social security program.

In this paper we have used specific functional forms for preferences and technologies. In particular, we assumed that all utility functions and technologies are Cobb-Douglas (but with private and public material inputs in education being perfect substitutes). In this we follow most of related theoretical literature. We believe that these models can potentially be applied to carry out a quantitative analysis of education policy issues. For this purpose it is crucial to have good estimates of education technology parameters including the elasticities of substitution between public and private inputs. The recent paper by Houtenville and Conway (2001) is a promising first step in this direction. 
We have assumed in this paper that both public education and the social security program act like a "linear tax": In each case, taxation rises linearly with income while government benefits are distributed in a lump-sum fashion. Arguably, neither public education nor social security are organized literally like that. Given differential longevity, which is positively correlated with wealth, social security tends to be regressive in the US, even though the formula used to allocate social security payments to the old is designed to make social security in the U.S. progressive. For a description and discussion of the distributive effects of the social security program in the US see Wolff (1987). There is no question that the institutional arrangements of public programs matter for their distributional outcomes. Our paper contributes to this understanding; we leave the analysis of models of public education and social security programs with more institutional details for future research. 


\section{References}

Atkinson, A.B., "On the Measurement of Inequality,” Journal of Economic Theory 2 (1970), 244-263.

Barro, R., "Government Spending in a Simple Model of Endogenous Growth,” Journal of Political Economy 98 (1990), 5103-5125.

Benabou, R., "Heterogeneity, Stratification, and Growth: Macroeconomic Implications of Community Structure and School Finance," American Economic Review 86 (1996), 584-609.

Biggs, M. and J. Dutta, “The distributional effects of education expenditures," National Institute Economic Review 0, no. 169 (1999), 68-77.

Boldrin, M., "Public Education and Capital Accumulation,” Discussion Paper No.1017, Northwestern University, 1993.

Boldrin, M. and A. Montes Alonso, "The Intergenerational Welfare State. Public Education and Pensions," mimeo, University of Minnesota, 2000.

Card, D. and A. Krueger, "Does School Quality Matter? Returns to Education and the Characteristics of Public Schools in the United States," Journal of Political Economy, 100 (1992), 1-40.

Coons, J.E., Clune, W.H. and S.D. Sugarman, Private Wealth and Public Education (Cambridge, MA: Harvard University Press, 1970).

Cremin, L.A., ed., The Republic and the School: Horace Mann on the Education of Free Men (New York: Teachers' College Press, 1957).

Eckstein, Z. and I. Zilcha, “The Effects of Compulsory Schooling on Growth, Income Distribution and Welfare," Journal of Public Economics 54 (1994), 339-359. 
Fernandez, R. and R. Rogerson, "Income Distribution, Communities, and the Quality of Public Education," The Quarterly Journal of Economics 111 (1996), 135-164.

Feldstein, M., "Social Security, Induced Retirement, and Aggregate Capital Formation," Journal of Political Economy 23 (1974), 905-926.

, "Social Security and Private Saving: Reply," Journal of Political Economy 90 (1982), 630-652.

Glomm, G. and M. Kaganovich, "Income Distribution Effects of Public Education and Social Security in a Growing Economy,” mimeo, Indiana University, 2001.

Glomm, G. and B. Ravikumar, "Public vs. Private Investment in Human Capital: Endogenous Growth and Income Inequality," Journal of Political Economy 100 (1992), 818-834.

Hanushek, Ch., K. Leung and K. Yilmar, "Redistribution Through Education and Other Transfer Mechanisms," Working Paper 8588, NBER, 2001.

Houtenville, A. J. and K. Smith Conway, "Parental Effort, School Resources and Student Achievement," mimeo, Cornell University, 2001.

Hubbard, R.G. and K.L. Judd, "Social Security and Individual Welfare: Precautionary Saving, Borrowing Constraints, and the Payroll Tax," American Economic Review 77 (1987), 630-646.

Kaganovich, M. and I. Zilcha, "Education, Social Security, and Growth," Journal of Public Economics 71 (1999), 289-309.

Karni, E. and I. Zilcha, "Aggregate and Distributional Effects of Fair Social Security," Journal of Public Economics 40 (1989), 37-56.

Kurland, P.B., "Equal Educational Opportunity: The Limits of Constitutional Jurisprudence Undefined," University of Chicago Law Review 35 (1968), 583-600. 
Laitner, J., "Bequests, Gifts and Social Security," Review of Economic Studies 55 (1988), 275299.

Laitner, J., "Wealth Accumulation in the US: Do Inheritances and Bequests Play a Significant Role?" Mimeo, University of Michigan, 2001.

LeGrand, J., The Strategy of Equality Redistribution and the Social Services (London: George Allen and Unwin, 1982).

Loury, G., "Intergenerational Transfers and the Distribution of Earnings," Econometrics 49 (1981), 843-867.

Lucas, R.E., Jr., “On the Mechanics of Economic Development,” Journal of Monetary Economics 22 (1988), 3-42.

Miron, J. and D.N. Weil, “The Genesis and Evolution of Social Security,” in Bordo, M.D., C. Goldin and E.N. White, eds., The Defining Moment: The Great Depression and the American Economy in the Twentieth Century (Chicago: University of Chicago Press, 1998), 297-322.

Pecchenino, R.A. and K.R. Utendorf, "Social Security, Social Welfare and the Aging Population," Journal of Population Economics 12 (1999), 607-623.

Persson, T. and G. Tabellini, "Is Inequality Harmful for Growth? Theory and Evidence," American Economic Review 48 (1994), 600-621.

Rios-Rull, J.-V., “Comment on "Inequality and Growth",” NBER Macroeconomics Annual, 1996.

Rothschild, M. and J. Stiglitz, "Some Further Results on Measurement of Inequality” Journal of Economic Theory 6 (1973), 188-204.

Soares, J., "Public Education Reform: Community, State or National Funding of Education," mimeo, George Washington University, 2001. 
Thurow, L., "Education and Economic Equality," Public Interest 78 (1972), 66-81.

Tsiddon, D. and Y. Rubinstein, "Coping with Technological Progress: The Role of Ability in Making Inequality so Persistent,” CEPR Discussion Paper No.2153, 1999.

Wolff, Nancy, Income Redistribution and the Social Security Program (Ann Arbor: University of Michigan Research Press, 1987).

Zhang, J., "Optimal Public Investments in Education and Endogenous Growth,” Scandinavian Journal of Economics 98 (1996), 387-404.

Zhang, J. and J. Zhang, "Social Security, Intergenerational Transfers, and Endogenous Growth," Canadian Journal of Economics 31 (1998), 1225-1241.

Zilcha, I., "Intergenerational Transfers, Economic Growth and Income Distribution," in Koch, K.-J. and K. Jaeger, eds., Trade, Growth, and Economic Policy in Open Economies: Essays in Honor of Hans-Jurgen Vosgerau (Heidelber: Springer, 1998), 111-121. 


\section{Appendix 1}

\section{Proof of Propositions 3.1. and 3.2}

Let $h_{t}(T, J, 2)$ stand for the realizations of $h_{t}(T)$ corresponding to given values of $J$ and 2. According to the relationships (3.9) and (3.11) the Lorenz curve ranking of the distribution of $h_{t}(T, J, 2)$ is equivalent to such ranking of the distribution of the expression

$$
\left(\frac{\alpha_{3}(\omega) \sigma}{\alpha_{1}+\alpha_{2}+\alpha_{3}(\omega) \sigma}\right)^{\sigma}\left[\frac{h_{t}(\omega, \tau, \theta)}{H_{t}}+a(\tau, \theta)\right]^{\sigma}
$$

where $\mathrm{a}(\mathrm{J}, 2)$ was defined in (3.8). Further, according to Lemma 3.3, this ranking is equivalent to the Lorenz curve ranking of the distribution of the expression

$$
\left[\frac{h_{t}(\omega, \tau, \theta)}{H_{t}}+a(\tau, \theta)\right]^{\sigma}
$$

First we observe, that $\frac{\partial a}{\partial \theta}=\frac{\delta(1-\delta) \alpha_{2} C}{\left[\delta+\left(1-\alpha_{2} C\right) \theta(1-\delta)\right]^{2}}>0$ and proceed to prove part (ii) of Proposition 3.1. Let tax rate 2 change from an original value $2_{0}$ to $2_{1}>2_{0}$. We need to prove that

$$
\mathrm{h}_{\mathrm{t}+1}\left(\tau, \theta_{1}\right) \quad>_{\mathrm{L}} \quad \mathrm{h}_{\mathrm{t}+1}\left(\tau, \theta_{0}\right) \quad \text { for } \mathrm{t}=0,1, \ldots
$$

or, equivalently, that

$$
\left[\frac{\mathrm{h}_{\mathrm{t}}\left(\tau, \theta_{1}\right)}{\mathrm{H}_{\mathrm{t}}\left(\tau, \theta_{1}\right)}+\mathrm{a}\left(\tau, \theta_{1}\right)\right]^{\sigma}>_{\mathrm{L}}\left[\frac{\mathrm{h}_{\mathrm{t}}\left(\tau, \theta_{0}\right)}{\mathrm{H}_{\mathrm{t}}\left(\tau, \theta_{0}\right)}+\mathrm{a}\left(\tau, \theta_{0}\right)\right]^{\sigma} .
$$

Since $a(J, 2)$ strictly decreases in 2, a straightforward application of Lemmas 3.1 and 3.2 yields that ( 4 ) is true for $\mathrm{t}=0$ and thereby ( 3 ) is true for $\mathrm{t}=0$. We now apply the induction argument. Assume that the relationship $h_{t}\left(J, 2_{1}\right)>_{L} h_{t}\left(J, 2_{0}\right)$ has been established for some $t$. Then it is also true that $h_{t}\left(J, 2_{1}\right) / H_{t}\left(J, 2_{1}\right)>_{L} h_{t}\left(J, 2_{0}\right) / H_{t}\left(J, 2_{0}\right)$ since $H_{t}(J, 2)$ is the mean of the 
distribution of $h_{t}(J, 2)$ (hence the division does not affect the relationship between the Lorenz curves of the distributions). Therefore, applying Lemmas 3.1 and 3.2 we get the dominance inequality (4) which is equivalent to $h_{t+1}\left(\tau, \theta_{1}\right)>_{L} h_{t+1}\left(\tau, \theta_{0}\right)$. This completes the induction argument and the proof of Proposition 3.1(ii).

The proof of part (i) of Proposition 3.1 and of the entire Proposition 3.2 follow the procedure identical to the above and are based on the fact that $\frac{\partial \mathrm{a}}{\partial \tau}=\frac{\partial \mathrm{a}}{\partial \theta} \cdot \frac{\partial \theta}{\partial \tau}$, hence $\frac{\partial \mathrm{a}}{\partial \tau}$ has the sign of $\frac{\partial \theta}{\partial \tau}$. Indeed, under the provisions of Proposition 3.1(i), $\frac{\partial \mathrm{a}}{\partial \tau}=0$. In case of Proposition 3.2(i) $\frac{\partial \mathrm{a}}{\partial \tau}<0$, while in part (ii) of Proposition 3.2 a(J,2) / 0 since $2=0 . \mathrm{S}$ 


\section{Appendix 2}

The vertical axis in the figures below measures the value of the expression $A_{2}(\tau, \theta)$, i.e., the constant term in relationship (4.14).

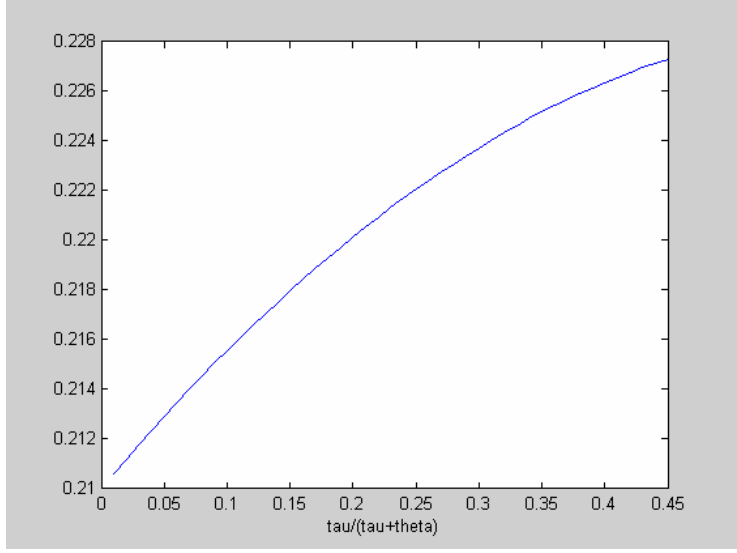

Figure 1. Higher public education funding decreases inequality Parameters: $\alpha_{1}=\alpha_{2}=1, \mathrm{D}=0.45, \delta=0.3, \sigma=0.9, \mathrm{~b}=1, \tau+\theta=0.2$.

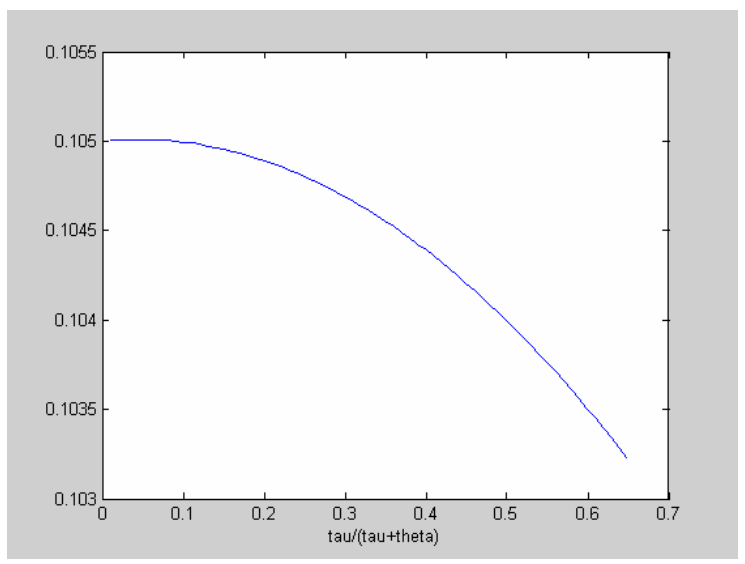

Figure 2. Higher public education funding increases inequality Parameters: $\alpha_{1}=\alpha_{2}=1, D=0.45, \delta=0.3, \sigma=0.99, b=2, \tau+\theta=0.1$. 


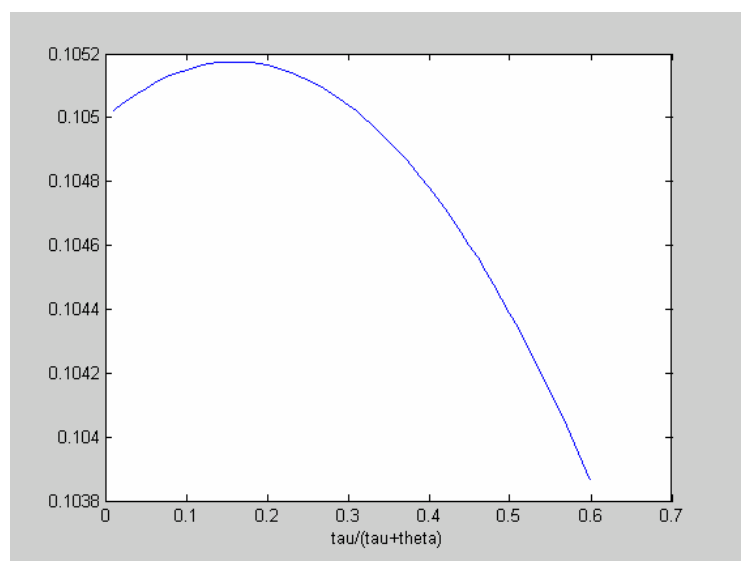

Figure 3. Non-monotonic relationship between public education funding and inequality.

Parameters: $\alpha_{1}=\alpha_{2}=1, D=0.45, \delta=0.3, \sigma=0.9, b=1.5, \tau+\theta=0.1$. 